\title{
Outcome of Alvarado scoring system in the diagnosis of acute appendicitis at a tertiary care teaching hospital
}

\author{
AFZA SALEEM ${ }^{1}$, ZAHRA ALI $^{2}$, WASIF MAJEED CHAUDHRY ${ }^{3}$, ARUJ ALAM ${ }^{4}$, MUHAMMAD SHOAIB ${ }^{5}$, ZAHID MAHMOOD ${ }^{6}$ \\ 1,2 PG Trainee, Department of General Surgery, Lahore Medical and Dental college/ Ghurki Trust Teaching Hospital, Lahore, \\ ${ }^{3}$ Associate Professor of General Surgery, Lahore Medical \& Dental College/ Ghurki Trust Teaching Hospital, Lahore, Pakistan \\ ${ }^{4}$ Professor of General Surgery, Continental Medical College, Lahore, Pakistan \\ ${ }^{5}$ Professor of General Surgery, Azra Naheed Medical College, Lahore, Pakistan \\ ${ }^{6}$ Professor of General Surgery, Lahore Medical and Dental college / Ghurki Trust Teaching Hospital, Lahore, Pakistan \\ Correspondence to Dr. Afza Saleem, Email: dr.afza.saleem@gmail.com
}

\begin{abstract}
Background: Diagnosis of acute appendicitis is usually made on the basis of clinical judgment and experience of the surgeon. It may sometimes become a challenge due to variability in presentation. It is not unusual for surgical residents \& consultants to miss the diagnosis.

Aim: To evaluate the effectiveness of Alvarado score in making an accurate diagnosis of acute appendicitis and assessing its sensitivity at a tertiary care hospital, in Lahore, Pakistan.

Methods: A Prospective observational study was conducted at the department of Surgery, Ghurki Trust Teaching Hospital (GTTH). The data was collected from 117 patients on a self-designed proforma over a one-year period i.e., from $1^{\text {st }} \mathrm{January} 2018$ to $31^{\text {st }}$ December 2018 with the suspected diagnosis of acute appendicitis and who underwent surgery. The variables were evaluated with Alvarado scoring system to assess its effectiveness and sensitivity. The data was analyzed using SPSS vr 23.

Results: Demographic results showed $73(62.4 \%)$ males and $44(37.6 \%)$ female. The mean age was 23 years and most of the patient were in age group 11-20years 55(47\%). Abdominal pain was the commonest feature found in all the patients followed by Nausea in $72 \%$ and migration of pain to Right lliac fossa $60 \%$. Complicated appendicitis was found as gangrenous (7.5\%) and perforated (6\%). $53 \%$ of the cases were performed by on-call team consisted of SRs and surgical residents.

Conclusion: Alvarado score is an effective scoring system in making an accurate diagnosis of acute appendicitis. It can be very useful in the prompt management of patients with equivocal features and in extreme of ages.

Keywords: Acute appendicitis, Clinical scoring, Alvarado score
\end{abstract}

\section{INTRODUCTION}

Acute appendicitis is the commonest surgical emergency in tertiary care hospitals and takes most of the share amongst the differential diagnosis of acute abdomen ${ }^{1}$. Acute appendicitis is commonly caused by the obstruction of appendiceal lumen by a feacolith, lymphoid hyperplasia or a stricture ${ }^{2,25}$. The diagnosis of acute appendicitis, due to its variability in presentation, sometimes becomes a challenge. It is not unusual for the surgical residents and even consultants to sometimes miss the diagnosis ${ }^{6}$. Although the most common presentation of acute appendicitis is lower abdominal pain, yet the patients can also present with some atypical symptoms ${ }^{25}$. Accurate diagnosis of acute appendicitis is difficult in extremes of ages and women of reproductive age ${ }^{3}$. The clinical presentation varies with age, severity of inflammation and variable position of appendix. Acute appendicitis can occur in all age groups but it is most commonly seen in childhood and young adults with a peak incidence in the teens and early twenties 4,25 Common complications of acute appendicitis include perforation of appendix, gangrene, intra-abdominal abscess formation, wound infection and paralytic ileus ${ }^{3}$. Early diagnosis and treatment can effectively reduce these complications. Delay in making an accurate diagnosis of acute appendicitis can result in increased morbidity while a wrong diagnosis may lead to negative appendectomies. Clinical judgment is the mainstay in the diagnosis of acute appendicitis but total leucocyte count, ultrasound and computed tomography scan aid in confirming the diagnosis. The diagnostic accuracy can best be achieved with ultrasound and CT imaging ${ }^{4}$. CT scan is useful in confirming the diagnosis of acute appendicitis in patients with equivocal symptoms, thus reducing the rate of complications and unnecessary appendectomies on one hand while establishing an alternative diagnosis on the other ${ }^{5}$. Since CT scan is not easily accessible and as it increases the management cost in developing countries different scoring systems have been used in making early diagnosis of acute appendicitis. Alvarado scoring system is the most popular and

Received on 14-05-2021

Accepted on 24-09-2021 commonly used criteria for diagnosing acute appendicitis ${ }^{6,7}$. This scoring system has a very good sensitivity and specificity when applied to the western population ${ }^{8}$. The objective of this study was to evaluate the effectiveness and also to assess the sensitivity of the Alvarado score in the diagnosis of acute appendicitis in a tertiary care hospital setting in Lahore, Pakistan.

\section{MATERIAL \& METHODS}

This was a cross sectional validation study in which prospective data was analyzed. It was conducted in the department of surgery, Ghurki Trust Teaching Hospital (GTTH). The ethical approval of this study was taken from the institutional ethical review board.

Data collection: The data was collected prospectively on a selfdesigned proforma from 117 patient's hospital record, admitted during a one-year period i.e., from $1^{\text {st }}$ January 2018 to $31^{\text {st }}$ December 2018 with suspected diagnosis of acute appendicitis and underwent surgery. Patients from all age groups and of both genders were included in the study with the exception for previously diagnosed and suspected cases of chronic inflammatory bowel disease and pregnant females. Patient's age, gender, clinical features, ultrasound findings, total leucocytes count, type of incision and procedure, level of surgeon, pre-operative findings and early postoperative complications were recorded. The diagnosis of acute appendicitis was made based on the findings on history and clinical examination. Symptoms recorded were lower abdominal pain, migratory pain, anorexia, nausea, vomiting and fever. Clinical signs included tenderness in right iliac fossa, rebound tenderness, Rovsing's sign and Psoas sign. Total leukocyte count and neutrophil left shift was recorded in findings as well. Diagnosis was confirmed on per-operative findings. Different surgical procedures were performed depending on the clinical criteria. The procedures included open appendectomy, laparoscopic appendectomy and laparotomy. The procedures were performed by senior registrars, surgical residents and only few by consultants. Patient's individual variables were evaluated and compared with Alvarado score. 
Statistical analysis: The collected data was analysed using SPSS version 23. The observations were analysed using descriptive Statistical methods.

\section{RESULTS}

One hundred and seventeen patients were admitted through the emergency department of GTTH with the diagnosis of acute appendicitis and they underwent various surgical procedures depending upon the clinical criteria. Demographic results showed $73(62.4 \%)$ males and $44(37.6 \%)$ females. The mean age of these patient was 23 years (table. 1). In this study, most of the patients were in the age group of $11-20$ years $55(47 \%)$ followed by $28(24 \%)$ in the age group of 21-30 years (Fig.. 1). In the presenting symptoms, history of lower abdominal pain was the commonest feature found in all the patients followed by nausea $85(72 \%)$ and migration of pain to right iliac fossa $71(60 \%)$. Lower abdominal tenderness was elicited in $100 \%$ of the patients and guarding in the right iliac fossa was appreciated in $102(88 \%)$ patients. There was raised total leukocyte count (>9x109/L) in $79(68 \%)$ of patients and it was found to be higher ( $>18 \times 10^{9} /$ liter) in complicated patients like perforated and gangrenous appendix. Neutrophil left shift $(\geq 75 \%)$ was recorded in $90(76 \%)$ patients (Table.1). In perioperative data, the most commonly used incision was the Grid iron incision in $73(67 \%)$ of pts. Lap. appendectomy was performed in only five patients. Per-operative findings revealed acutely inflamed appendix in $100(85 \%)$ cases. Complicated appendicitis was found as gangrenous $(7.5 \%)$ and perforated (6\%). Laparotomy with midline incision was performed in 4 patients with developed peritonitis in delayed presentation and found to have perforated appendix (Table 2). The length of hospital stay ranged between 2-9 days with mean 3.2 days. $60 \%$ patients had length of stay $\leq 3$ days. In early postop complications, paralytic ileus developed in $16(13.5 \%)$ patients. 6 patients developed fever in early postoperative period and these patients had complicated appendicitis. Wound sepsis occurred in $9(7.5 \%)$ patients. No mortality was recorded in patients presenting with clinical features of acute appendicitis and who underwent surgery in this study period. Alvarado scoring system (AS) was applied to all these diagnosed patients of acute appendicitis. On evaluation four cases were found to have score equal to 4 according to Alvarado scoring criteria. 37 cases out of a total of 117 pts had a AS of 5-6, while 4 cases were negative for acute appendicitis confirmed at operative findings (Fig. 2), and the remaining $85(72 \%$ ) pts had a AS $\geq 7$ (Table. 3 ). Keeping a cutoff point at 7 for accurate diagnosis of acute appendicitis with data collected diagnostic Sensitivity of Alvarado score (i.e., correct diagnoses/total cases) was calculated at $75.22 \%$ (Table. 4).

Figure.1: Demographic Distribution AGE \& GENDER DISTRIBUTION

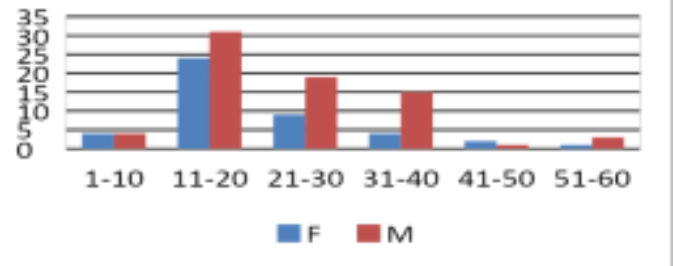

Table 1: Demographics and Clinical findings $(n=117)$

\begin{tabular}{|l|l|}
\hline Demographics & 23 \\
\hline Mean Age & $73: 44$ \\
\hline Gender ratio M:F & $117(100 \%)$ \\
\hline Clinical features & $71(60 \%)$ \\
\hline Abdominal pain & $85(72 \%)$ \\
\hline Migratory Pain & $63(54 \%)$ \\
\hline Nausea & $57(48 \%)$ \\
\hline Vomorexia & $44(38 \%)$ \\
\hline Fever & $102(87 \%)$ \\
\hline Guarding & $117(100 \%)$ \\
\hline RIF tenderness & $109(93 \%)$ \\
\hline Rebound Tenderness & $26(22 \%)$ \\
\hline Psoas sign &
\end{tabular}

Table 2: Peri-operative Data $(\mathrm{n}=117)$

\begin{tabular}{|l|l|}
\hline Intraoperative Findings & $98(83 \%)$ \\
\hline Acutely Inflamed & $8(7.5 \%)$ \\
\hline Gangrenous & $7(6 \%)$ \\
\hline Perforated & $4(3.5 \%)$ \\
\hline Normal & $73(67 \%)$ \\
\hline Incision & $3(2.5 \%)$ \\
\hline Grid iron incsion & $27(23 \%)$ \\
\hline Lanz incision & $2(1.5 \%)$ \\
\hline Transverse skin crease incision & $2(1.5 \%)$ \\
\hline Lower Midline incision & $5(4 \%)$ \\
\hline Midline umbilical saving incision & $62(53 \%)$ \\
\hline Laparoscopic appendectomy & $39(33 \%)$ \\
\hline Surgeon level & $14(12 \%)$ \\
\hline Postgraduate trainee & $2(1.5 \%)$ \\
\hline Senior Registrar & \\
\hline Assistant Professor & $5(4 \%)$ \\
\hline Professor & $108(92 \%)$ \\
\hline Procedures & $4(3 \%)$ \\
\hline Laparoscopic Appendectomy & $16(13.5 \%)$ \\
\hline Open Appendectomy & $6(5 \%)$ \\
\hline Laparotomy & $9(7.5 \%)$ \\
\hline Early postoperative complications & \\
\hline Ileus & \\
\hline Post-op Fever & \\
\hline Wound sepsis &
\end{tabular}

Figure 2: AS relationship to preoperative findings

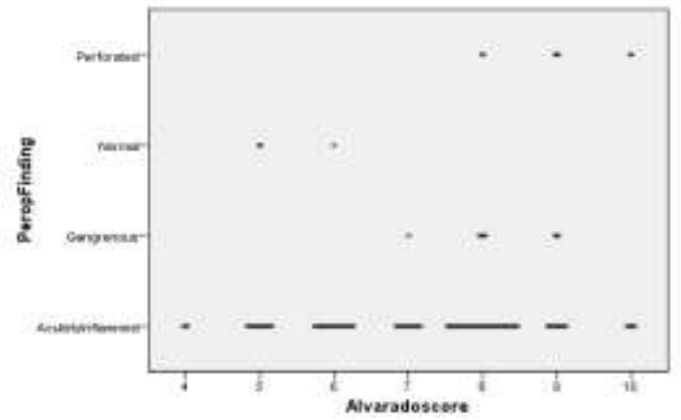

Table 3: Evaluation of Alvarado Score to individual variables in Diagnosis of Acute Appendicitis

\begin{tabular}{|l|c|c|}
\hline Clinical Features & $\begin{array}{c}\text { Alvarado } \\
\text { Score }\end{array}$ & $\begin{array}{c}\text { Distribution of Data for } \\
\text { individual variables } \mathbf{n = 1 1 7}\end{array}$ \\
\hline Migratory Pain & 1 & $71(60 \%)$ \\
\hline Anorexia & 1 & $63(54 \%)$ \\
\hline Nausea -Vomiting & 1 & $57(48 \%)$ \\
\hline Tenderness in RIF & 2 & $117(100 \%)$ \\
\hline Rebound Tenderness & 1 & $109(93 \%)$ \\
\hline Elevated Temperature & 1 & $44(37 \%)$ \\
\hline TLC $\geq 10 \times 109 / L$ & 2 & $79(68 \%)$ \\
\hline Neutrophil Shift $\geq 75 \%$ & 1 & $90(76 \%)$ \\
\hline \multicolumn{2}{|c|}{$\leq 4$ not likely } & $5-6$ likely $7-8$ probable $\geq 9$ definite \\
\hline
\end{tabular}

Figure 3: AS relationship to Neutrophil left Shift

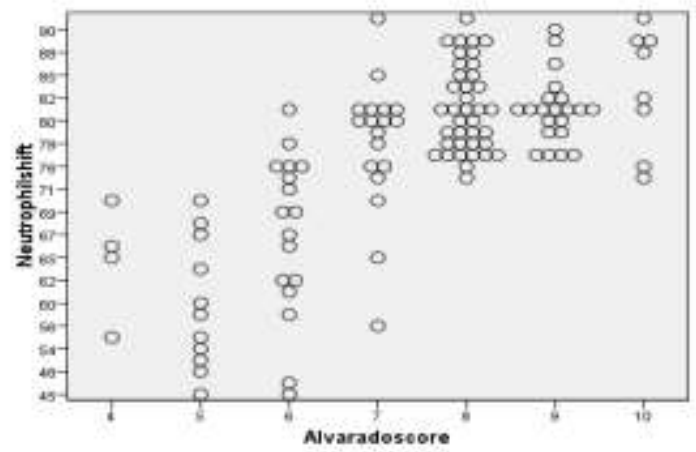


Table 4: Interpretation of Alvarado score with number of Diagnosis

\begin{tabular}{|l|c|}
\hline Alvarado Score & No. of Diagnosis $\mathbf{n = 1 1 7}$ \\
\hline$\leq 4$ not likely & $4(3.5 \%)$ \\
\hline 5-6 likely & $28(23 \%)$ \\
\hline$\geq 9$ probable & $56(47 \%)$ \\
\hline
\end{tabular}

\section{DISCUSSION}

Acute appendicitis is a common surgical condition which is diagnosed mostly by clinical examination and supported by the laboratory findings. Different diagnostic methods are used to improve accuracy like ultrasound, CT scan, but all these methods have some drawbacks. These methods are operator dependent and increase the cost of treatment or even delay the management 5. In developing countries like Pakistan, where there is limitation of resources these methods are not cost effective ${ }^{13}$. CT scan is the gold standard investigation to diagnose acute appendicitis. Most of the patients are operated without a CT scan due to its high cost, non-affordability and non-availability in most of the hospitals in Pakistan. This practice may lead to some unnecessary operations and therefore high morbidity ${ }^{9}$. In this study, there was no major morbidity recorded and the negative appendectomy rate was $3.4 \%$. This negative appendectomy rate is well within range of different studies in literature ${ }^{10,11}$

In the recent years, development of different scoring systems has eased evaluation of patients presenting with pain in the right iliac fossa. The Alvarado Score is the most commonly used scoring system. Its validity and sensitivity has been determined in many studies ${ }^{12,13,14}$. It is easy to apply Alvarado scoring system as clinical findings are already in practice. In this study, the Alvarado scoring system was applied to the clinically diagnosed cases of acute appendicitis. The diagnostic sensitivity of this score was found to be $75.22 \%$ in this study which is comparable to other studies in the literature ${ }^{15,18}$. Kariman et al. ${ }^{19}$ reported that the patients presenting with acute abdominal pain and evaluated for Alvarado score $>7$ are $93 \%$ more likely to be diagnosed as acute appendicitis than patients with Alvarado score $<7$ have $26 \%$ chances to be diagnosed as acute appendicitis. Therefore, patients making lesser scores than 7 should be cautiously worked up not to miss a diagnosis. In this study, 85 (72\%) patients were evaluated as Alvarado score more than 7. 4 patients had an Alvarado score $<4$ and out of these 4 only one patient was found to have normal appendix in operative findings and the other three were acutely inflamed appendixes. Three patients who were found to have normal appendix were at Alvarado score-5 when evaluated. A significant Neutrophilic left shift $\geq 75 \%$ observed in our study (Figure 3 ) is in true comparison with study by Wang et al ${ }^{20,21}$. In literature, different scoring system have been evaluated but the Alvarado scoring system is easy to apply and more practical $\left.\right|^{8,23,24}$

\section{CONCLUSION}

Alvarado score is an effective scoring system in making an accurate diagnosis of acute appendicitis. It can be useful in the prompt management of patients with equivocal features and in extreme of ages. Clinical scoring systems may enhance the accuracy in diagnosis, but still good clinical acumen will keep primary importance in making diagnosis of acute appendicitis. Application of clinical scoring systems like AS can benefit young trainees to develop their skills in diagnostic accuracy and prompt management for this common surgical emergency minimizing morbidity due to missed or delay in diagnosis

Limitation: The study is prospective and has been conducted at a single hospital on a small group of patients. A multicentric study with a large sample size is suggested for a more accurate evaluation of the efficacy of the Alvarado scoring system.

Conflict of Interest: No conflict of interest was declared

Financial Disclosure: This study has received no financial support from any external organization.

\section{REFERENCES}

1. Ali MZ, Maddu VK. Comparative analysis of clinical, radiological and operative findings in acute abdomen. International Surgery Journal. 2019 Feb 25;6(3):806-11.

2. Nema P. Jain AK. Clinical comparative study of different scoring system in acute appendicitis. IntSurg J. 2016Feb;3(1): 184-188.

3. Becker P. Fichtner-Feigl S. Schilling D. Clinical Management of Appendicitis. Visc Med 2018;34: 453-458

4. Kalan M, Talbot D, Cunliffe WJ, Rich AJ. Evaluation of Modified Alvarado Score in Diagnosis of Acute appendicitis; a prospective study. Ann R Coll Sur Engl. 1994;76:418-19

5. Al-khayal KA, Al-Oman MA. Computed tomography and ultrasonography in the diagnosis of equivocal acute appendicitis. A meta analysis. Saudi Med J. 2007 Feb;28(2):173-80

6. Alvarado A. A practical score for the early diagnosis of acute appendicitis. Ann Emerg Med. 1986;15:557-64

7. Christian F, Christian GP. A simple scoring system to reduce the negative appendicectomy rate. Ann R CollSurg Engl. 1992;74:281-5

8. Owen TD, Williams H, Stiff G, Jenkinson LR, Rees BI. Evaluation of the Alvarado score in acute Appendicitis. J R Soc Med.1992;85:87-88

9. Douglas CD, Macpherson NE, Davidson PM, Gani JS. Randomised controlled trial of ultrasonography in diagnosis of acute appendicitis, incorporating the Alvarado score. BMJ. 2000; 321: 919-922

10. Kessler N, Cyteval C, Gallix B, Lesnik A, Blayac PM, Pujol J, Bruel JM, Taourel P. Appendicitis: Evaluation of sensitivity, specificity, and predictive values of US, Doppler US, and laboratory findings. Radiology. 2004; 230: 472-478.

11. Khan MN, Davie E, Irshad K. The role of white cell count and Creactive protein in the diagnosis of acute appendicitis. J Ayub Med Coll Abbottabad. 2004; 16: 17-19.

12. Ali S, Malik Z, Niaz MMA, Ahmed N. Validity of alvarado score in diagnosing acute appendicitis. Professional Med $\mathrm{J}$ Feb 2013;20(1):001-005

13. Khan I, Rehman A. Application of Alvarado scoring system in diagnosis of acute appendicitis. J Ayub Med. Coll Abbottabad.2005;17:41-4.

14. Talukder DBI, Siddiq. Modified Alvarado scoring System in the diagnosis of acute appendicitis. JAFMC Bangl. 2009 Jun;5(1):18-20.

15. Wu Xingye, Li Yuqiang, Wang Rong and Zhang Hongyu. Evaluation of Diagnostic Scores for Acute Appendicitis . Journal of the College of Physicians and Surgeons Pakistan 2018, Vol. 28(2): 110-114

16. Z.A. Memonet al. Acute Appendicitis: Diagnostic accuracy of Alvarado scoring System. Asian J. of Surg. 2013;36:144-149

17. Limpawattanasiri C. Alvarado score for the acute appendicitis in a provincial hospital. J Med Assoc Thai. 2011;94:441-448.

18. Shah SWA, Khan CA, Malik SA, Waqas A, Tarrar AM, Bhutta IA Modified Alvarado score: accuracy in diagnosis of acute appendicitis in adults. Prof Med J.2010;17:546-550

19. Kariman H, Shojaee M, Sabzghabaei A, Khatamian R, Derakhshanfar $\mathrm{H}$, Hatamabadi $\mathrm{H}$. Evaluation of the Alvarado score in acute abdominal pain. UlusTravmaAcilCerrahiDerg 2014;20:86-90

20. Wang LT, Prentiss KA, Simon JZ, Doody DP, Ryan DP. The use of white blood cell count and left shift in the diagnosis of appendicitis in children. PediatrEmerg Care. 2007; 23: 69-76

21. BassemAbouMerhi, Mahmoud Khalil , Nabil Daoud. Comparison of Alvarado Score Evaluation and Clinical Judgment in Acute Appendicitis. Med Arh. 2014 Feb; 68(1): 10-13

22. N. Baidya, G. Rodriguez, A. Rao, S. A. Khan. Evaluation of Alvarado score in acute Appendicitis: a prospective study. Internet J Surg, 2007;9:1-6

23. Chan MY, Tan C, Chiu MT, Ng YY. Alvarado score: an admission criterion in patients with right iliac fossa pain. Surgeon. 2003; 1: 39-41.

24. Sooriakumaran $\mathrm{P}$, Lovell D, Brown R. A comparison of clinical judgment $\mathrm{Vs}$ the modified Alvarado score in acute appendicitis. Int $\mathrm{J}$ Surg. 2005; 3: 49-52.

25. Williams NS, O Connell PR, McCaskie AW, Bailey \& Loves short practice of surgery. CRC Press - Taylor \& Francis Group, Boca Raton, 2018. 